\title{
A PRÁTICA DOCENTE NA VOZ DOS PROFESSORES: ECOS FORMATIVOS E CONTEXTUAIS
}

\author{
FERNANDA FRANZOLIN \\ ORCID: https://orcid.org/0000-0001-8808-9107 \\ CARLOS TOSCANO ${ }^{2}$ \\ ORCID: https://orcid.org/0000-0003-0815-1586
}

\begin{abstract}
RESUMO: O presente trabalho tematiza a compreensão das contribuições da formação de professores para o Ensino de Ciências nos Anos Iniciais do Ensino Fundamental e as condições de possibilidade de seu ensino. Para tanto, realizamos entrevistas junto aos seus protagonistas, os(as) professores(as) no município de Londrina/PR, entre 2010-2011. Trata-se de um estudo local e temporal, possibilitando compreender aspectos da realidade desse contexto e momento. Após a transcrição das entrevistas, houve a imersão no seu conteúdo, envolvendo um aprofundamento da leitura das respostas. A partir da imersão nos dados, houve a elaboração de algumas categorias, que foram quantificadas e organizadas em gráficos e tabelas que permitissem a análise. Dentre os resultados obtidos, cabe destacar que os estágios e o exercício da profissão são os locais e momentos privilegiados no aprendizado da profissão. Esta amostra permitiu identificar diferentes realidades quanto ao número de alunos por classe e horas-aula em Ciências. Apesar do grande interesse das crianças por Ciências Naturais, outras disciplinas são priorizadas. Por fim, defendeu-se tanto a valorização de uma formação para a prática docente quanto melhores condições para a docência.
\end{abstract}

Palavras-chave: Ensino de Ciências, Anos Iniciais do Ensino Fundamental, formação de professores, condições de trabalho docente.

\section{TEACHING PRATICE IN THE TEACHER'S VOICE: ECHOES OF THE TEACHING TRAINING AND TEACHING CONTEXT}

\begin{abstract}
The present work focuses on understanding the contributions of teacher education to Elementary School science teaching and teaching conditions. For this purpose, we conducted interviews with their protagonists, the teachers in the city of Londrina (Paraná, Brazil), between 2010 and 2011. This is a local study, making it possible to understand aspects of the reality of this context and moment. After transcribing the interviews, we immersed in their content, deeply reading their responses. From the immersion in the data, we developed some categories, which were quantified and organized in graphs and tables for the analysis. From the data, we highlight that school placement and professional work are privileged experiences for professional learning. Our sample allowed us to identify different realities
\end{abstract}

\footnotetext{
${ }^{1}$ Universidade Federal do ABC (UFABC). Santo André, SP, Brasil. <fernanda.franzolin@ufabc.edu.br>

${ }^{2}$ Universidade Estadual de Londrina (UEL). Londrina, PR, Brasil. <ctos12@gmail.com> 
concerning the number of students per class and class hours in science. Despite children's great interest in natural sciences, other disciplines are prioritized. Finally, we defend both the valuing of a teacher education that contributes to teachers' practice and better working conditions for teaching.

Keywords: Science teaching, Primary School, teacher education, teachers’ working conditions.

\section{LA PRÁCTICA DOCENTE EN LA VOZ DE LOS PROFESORES: ECOS FORMATIVOS Y CONTEXTUALES}

RESUMEN: Este artículo se centra en la comprensión de las condiciones de la formación del profesorado para la enseñanza de las Ciencias Naturales en los primeiros años de la Educación Primaria y las condiciones para la posibilidad de enseñarlas. Para ello, entrevistamos a sus protagonistas, los profesores y profesoras del municipio de Londrina (Paraná, Brasil), entre 2010-2011. Se trata de un estudio local y temporal, que permite entender aspectos de la realidad de este contexto y momento. Después de transcribir las entrevistas, se realizó una inmersión en su contenido, lo que implicó en una lectura más profunda de las respuestas. A partir de la inmersión en sus datos, hubo la elaboración de algunas categorías, las cuales fueron cuantificadas y organizadas en gráficos y tablas que permitieran el análisis. Entre los resultados obtenidos, cabe destacar que las prácticas supervisadas y el ejercicio de la profesión son momentos privilegiados para el aprendizaje de la profesión. Nuestra muestra nos permitió identificar diferentes realidades en cuanto al número de alumnos por aula y de horas de clase de Ciencias. A pesar del gran interés de los niños por las Ciencias Naturales, se priorizan otras disciplinas. Por fin, se defendió tanto la valoración de una formación docente para la práctica, como mejores condiciones para la docencia.

Palabras clave: Enseñanza de las Ciencias, Primeros Años de la Educación Primaria, formación de profesores, condiciones de trabajo docente. 


\section{INTRODUÇÃO}

Este artigo apresenta dados do projeto de pesquisa "O Ensino de Ciências nos Anos Iniciais no Ensino Fundamental na voz de seus professores". Dentro do escopo mais amplo do projeto, o estudo aqui relatado teve o objetivo de investigar o contexto formativo e as condições de trabalho na voz dos professores dos Anos Iniciais do Ensino Fundamental responsáveis pelo ensino de Ciências Naturais, no município de Londrina, Paraná. Mesmo diante da não contemporaneidade dos dados, que datam de 2010-2011, considera-se importante não os descartar e encaminhá-los à publicação, pois podem permitir a compreensão do retrato da localidade investigada em um determinado momento. Ademais, torná-los públicos pode possibilitar a outros pesquisadores diálogos com dados mais recentes ou com futuras pesquisas, permitindo a compreensão de mudanças ou da estabilidade das situações evidenciadas. Para tanto, serão destacados alguns aspectos relativos à formação de professores para os Anos Iniciais do Ensino Fundamental com destaque para o aspecto relativo ao ensino de Ciências.

Ao analisar a produção acadêmica a respeito do ensino de Ciências no curso de Pedagogia, tendo como base a Biblioteca Digital Brasileira de Teses e Dissertações (2006 a 2014), Batista e Lima (2017) identificaram que pesquisadores consideram escassa a carga horária destinada ao Ensino de Ciências nos cursos de Pedagogia, gerando, consequentemente, uma lacuna na formação docente para lecionar esta área de conhecimento. Em outro estudo realizado nos últimos anos por Carvalho e Ramalho (2018), verificou-se que professores dos Anos Iniciais também consideram que o domínio de conteúdos específicos durante a formação é algo importante para se ensinar Ciências. Questões históricas relacionam-se aos resultados obtidos por esses estudos mais recentes e aos dados aqui coletados há aproximadamente dez anos.

A formação específica dos professores que atuam nos primeiros anos do hoje denominado Ensino Fundamental passou por um histórico de transformações ao longo destes três últimos séculos e, especificamente, durante as últimas décadas. Segundo Saviani (2009), o primeiro estabelecimento destinado à formação de professores surgiu no século XVII na França. Já a primeira Escola Normal se instalou em Paris, em 1785, sendo que apenas no século XIX é que houve a consolidação das Escolas Normais.

No Brasil, logo após a Independência, surge a primeira Escola Normal. As primeiras escolas de formação deveriam prover coordenadas pedagógico-didáticas, porém concentraram-se em garantir o domínio dos conhecimentos a serem transmitidos aos alunos nas escolas de primeiras letras (SAVIANI, 2009). Seu currículo era constituído inicialmente por leitura, escrita, as quatro operações, decimais, proporções, geometria, gramática, geografia, princípios da moral cristã e religião (PROVÍNCIA DO RIO DE JANEIRO, 1835). Segundo Tanuri (2000), tratava-se de um currículo bastante rudimentar, que basicamente se restringia ao nível e ao conteúdo do primário, no qual os futuros professores atuariam. A formação pedagógica era limitada a uma única disciplina essencialmente prescritiva (Pedagogia ou Métodos de Ensino).

Até o fim de década de 60 do século XIX, a criação, a manutenção e a valorização dessas escolas não eram expressivas, o que só ocorreu a partir desse momento, com a ampliação do número de escolas da categoria e seu reconhecimento, visando a atender o anseio de formar professores para propiciar a popularização da educação primária. Com o Decreto 7.247, de 19/4/1879 (Reforma Leôncio de Carvalho), o currículo do curso ganha maior complexidade, incluindo, entre outras matérias: elementos de ciências físicas e naturais e de fisiologia e higiene; pedagogia e prática do ensino primário em geral; prática do ensino intuitivo ou lição de coisas (TANURI, 2000) - como se percebe, ainda predominavam os conhecimentos a serem transmitidos.

Posteriormente, na reforma da instituição pública do Estado de São Paulo em 1890, a preparação didático-pedagógica e a prática de ensino passaram a ser valorizadas, inclusive com a criação de uma escola-modelo anexa à Escola Normal. No entanto, essa preocupação ganhou força apenas com a reforma de 1932 e a criação dos Institutos de Educação, os quais tinham como objetivo não somente a formação de professores, mas também a pesquisa. Em seguida, esses institutos foram elevados ao nível superior e incorporados por universidades, quando então foram instituídos os cursos de Pedagogia. Nesse momento inicial, esses cursos funcionaram no modelo $3+1$, ou seja, três anos para a aprendizagem 
de conteúdos cognitivos que seriam ministrados nas aulas e um ano para a formação didática (SAVIANI, 2009).

Segundo Crespi e Nóbile (2018), o primeiro documento normativo a regulamentar o curso de Pedagogia no Brasil foi o Decreto-Lei n 1.190 de 4 de abril de 1939, que fundou a Faculdade Nacional de Filosofia da Universidade do Brasil, que comporia, dentre suas seções, a Seção de Pedagogia, responsável por este curso.

As Escolas Normais continuaram existindo com uma nova organização, que, de forma similar aos demais cursos secundários, dividiu esse curso em dois ciclos. O primeiro ciclo, correspondente ao ginasial (duração de quatro anos), contemplou um currículo centrado nas disciplinas de cultura geral, como ocorria nas antigas Escolas Normais. Já o segundo ciclo, correspondente ao colegial (duração de três anos), incluiu os fundamentos da educação propostos na reforma de 1932 (SAVIANI, 2009). De acordo com Hamburguer (2007), os egressos das Escolas Normais eram predominantemente do sexo feminino e tinham pouca formação em Ciências, preocupando-se em cumprir as exigências relacionadas à alfabetização e à aritmética.

Já na década de 1970, com a promulgação da Lei de Diretrizes e Bases (LDB) 5.692/71, houve a extinção das Escolas Normais e a criação da Habilitação em $2^{\circ}$. Grau para o Exercício do Magistério de $1^{\circ}$ Grau. A formação nesse curso consistia-se de um núcleo comum obrigatório para a formação no ensino secundário e uma parte diversificada contemplando especificamente a formação do professor. No mesmo momento, o curso de Pedagogia passou a formar, além daqueles profissionais que atuariam como formadores no curso de magistério, os especialistas em educação (diretores de escola, orientadores educacionais, supervisores escolares e inspetores de ensino) e os professores que lecionariam no $1^{\circ}$. Grau e na Educação Infantil (SAVIANI, 2009).

Posteriormente, a LDB 9.394/96 introduziu o curso superior de curta duração, denominado Curso Normal Superior, como alternativa para a formação de professores para atuar nas primeiras séries do então denominado Ensino Fundamental (BRASIL, 1996; SAVIANI, 2009). A partir dessa lei, houve um impulso na formação em nível superior, o que foi proporcionado tanto por políticas formativas quanto pela aterrorização causada pela ideia de que, após dez anos da vigência desse documento normativo, professores com formação apenas em nível secundário (Curso Normal ou Magistério) perderiam seu direito de lecionar, sendo necessária a formação em nível superior. Todavia, apesar da importância de se elevar a qualificação dos profissionais da educação, não há legitimidade para o impedimento da atuação dos formados em nível secundário, uma vez que possuem credencial para lecionar (BRASIL, 2003).

Hoje, segundo dados coletados no Censo Escolar de 2018, a maioria dos professores brasileiros que atuam nos Anos Iniciais do Ensino Fundamental têm nível superior completo com Licenciatura $(77 \%)$; e outra parcela corresponderia aos professores que têm sua formação completa até o Ensino Médio Normal ou Magistério (11\%) (BRASIL, 2019). Esses dados já são signifivamente diferentes do momento em que esta pesquisa foi efetuada, pois, no Censo Escolar de 2007, apenas metade dos professores brasileiros que atuam nos Anos Iniciais do Ensino Fundamental tinha formação em Pedagogia (50,1\%), e uma segunda considerável parcela seria a de professores que tinham sua formação completa até o curso Normal ou o Magistério (32\%) (BRASIL, 2009).

Segundo Saviani (2009), ao se analisarem as alterações relativas à formação docente, constata-se que, apesar da importância dada à questão pedagógica nos cursos de licenciatura, esta nunca foi satisfatoriamente contemplada, e o que fica evidenciado é a precariedade das soluções propostas nas políticas formativas. Para o autor, o grande problema foi a separação que ocorria no entendimento do processo formativo em dois aspectos que são indissociáveis da formação do professor: a forma (aspectos pedagógicos) e o conteúdo (os conhecimentos que os professores deveriam ensinar).

Hamburguer (2007) acredita que, apesar de a LDB 9.394/96 ter impulsionado a formação de professores em nível superior, o ensino de Ciências ainda não foi satisfatoriamente abordado nos cursos de formação desse nível de ensino, e, em consequência, tais profissionais apresentam dificuldades de tratar temas científicos nas salas de aula, assim como de conduzir experimentos e observações. Essa mesma questão também aparece no relato de outros pesquisadores (AUGUSTO; AMARAL, 2015; LANGHI; NARDI, 2005; LONGHINI, 2008). Ainda associado a essa problemática, o estudo realizado 
por Ramos e Rosa (2008) identificou uma outra dificuldade que diz respeito a se promover o ensino de Ciências fazendo uso da experimentação.

Gatti e Nunes (2009), ao analisarem os currículos e ementas dos cursos de Pedagogia de 71 instituições, verificaram que os conteúdos a serem ensinados nas disciplinas na educação básica - dentre eles, os conteúdos de ciências - aparecem esporadicamente, sendo genérica e superficialmente abordados nas disciplinas de metodologias e práticas de ensino. As autoras ressaltam, inclusive, que a fragilidade é maior nas ementas associadas ao ensino de Ciências, História e Geografia. Batista, Fusinato e Ramos (2016) identificaram que, dentre as instituições situadas no estado do Paraná, em média apenas 2,5\% das disciplinas do curso são voltadas à formação do pedagogo para a área de Ciências, sendo que, em quatro das nove instituições pesquisadas, este percentual se encontra abaixo de $1,8 \%$.

Deve-se salientar que não é somente a dissociação entre os aspectos pedagógicos e os conhecimentos específicos que os professores deveriam ensinar que gerou, e ainda gera, preocupação em torno da formação docente. Outra dissociação encontrada ao longo da história dos cursos formativos para professores refere-se à separação entre a teoria e a prática. Nos cursos de pedagogia estudados por Gatti e Nunes (2009), as pesquisadoras verificaram que predominam abordagens descritivas, havendo articulação insuficiente entre teoria e prática.

Cruz (2002) entrevistou pedagogos que se formaram nos tempos de implementação do curso de Pedagogia no Brasil e constatou que eles consideraram que esse curso deu maior ênfase aos fundamentos teóricos do que aos práticos. Isso seria, em parte, consequência da multiplicidade de estudos teóricos, que tanto possibilitou o desenvolvimento do domínio de conhecimento quanto contribuiu para a dispersão da própria pedagogia. Todavia, os entrevistados, que haviam também passado parte de sua formação nas Escolas Normais, consideraram que, na sua formação para docência "no curso Normal, predominou a ênfase na prática com muita teoria, ao passo que, no curso de pedagogia, predominou a ênfase na teoria com pouca prática” (CRUZ, 2002, p. 153).

Se, por um lado, a formação é um fator importante para a atuação do professor, por outro, ela não é a única questão a ser considerada quando se debruça na problemática da educação escolar. Há que se considerarem, inevitavelmente, as condições em que os profissionais da educação atuam. Nesse sentido, Paro (2012) apontou que condições de trabalho são imprescindíveis para se compreenderem os resultados da educação escolar:

Concentrar a atenção sobre a formação dos profissionais da educação como o problema mais importante da qualidade do ensino fundamental, como costumam fazer, em seu discurso, as autoridades governamentais responsáveis pelos sistemas de ensino, pode ser uma boa forma de obnubilar os reais determinantes do fracasso escolar, ou seja, as condições objetivas de trabalho (PARO, 2012, p. 598).

Saviani (2009) apresenta posicionamento similar, considerando que a questão da formação docente tem que ser analisada de forma indissociada das condições de trabalho do professor, envolvendo tanto as configurações relativas à jornada de trabalho quanto as demais condições concretas do trabalho docente na escola. Surge aqui um alerta para a falta de condições propícias à prática docente, o que, além de prejudicar a efetividade prática dos resultados de uma boa formação, pode desestimular os professores a investirem na dedicação ao seu aperfeiçoamento.

Para Paro (2003), os problemas relativos à educação escolar envolvem a formação adequada às diferentes funções, mas não se podem ignorar a disponibilidade e o uso de materiais específicos, recursos financeiros, a existência de espaço apropriado, a organização do uso dos tempos e espaços, o número de alunos por turma, os currículos e programas, os métodos de ensino utilizados, a organização do trabalho, além do desempenho e da satisfação do pessoal escolar e as relações de autoridade e poder na instituição.

O Censo Escolar de 2017, que traz dados específicos sobre as condições das escolas que atendem os Anos Iniciais do Ensino Fundamental, mostra a necessidade de se desenvolverem condições elementares de trabalho docente no Brasil. Apenas 52\% das escolas possuem sala dos professores, e $58 \%$ possuem secretarias. Laboratórios de informática estão presentes em apenas 44,7\% das escolas; e biblioteca ou sala de leitura, em apenas 49\%. Somente 27,5\% delas dispõem de área verde, sem contar 
que os dados mostram a existência de escolas sem energia elétrica, esgoto sanitário e abastecimento de água (BRASIL, 2017). Tanto os laboratórios de informática quanto as bibliotecas e os espaços verdes poderiam ser explorados nas aulas de Ciências (BUENO, 2017).

Outro aspecto influente é a importância dada ao Ensino de Ciências na educação básica. Assim como afirma Garcia et al. (2018), após 2001, o fato de as avaliações em larga escala nacionais envolverem exclusivamente as disciplinas de Língua Portuguesa e Matemática leva a políticas de distribuição desigual dos recursos entre as áreas de conhecimento, favorecendo o maior investimento em tempo formativo, criação de programas e projetos educacionais centrados nas duas referidas áreas.

Tendo em vista toda essa gama de questões relativas à educação escolar no que diz respeito ao percurso formativo e aos aspectos pertinentes à realidade cotidiana, esta pesquisa procurou ouvir os professores atuantes nessa etapa da escolaridade, no contexto específico do Município de Londrina (Paraná), entre os anos de 2010-2011.

\section{METODOLOGIA DA PESQUISA}

A pesquisa caracteriza-se por um estudo de cunho qualitativo-descritivo. A geração dos dados foi construída a partir de entrevistas com professores em que se tematizaram questões relativas ao percurso formativo e sua contribuição para o ensino de Ciências, sua experiência profissional, sua atual turma de alunos, as condições de trabalho e sua prática pedagógica. Para tanto, apoiou-se nas orientações de Thompson (1992) que norteiam o processo de construção do instrumento e da realização da entrevista, destacando que ela visa conhecer o que o entrevistado pensa e a importância da empatia para com ele, possibilitando-lhe elaborar suas respostas reflexivamente e em diálogo com o pesquisador.

A primeira etapa desta pesquisa consistiu no contato inicial com professores dos Anos Iniciais do Ensino Fundamental, convidando-os a serem entrevistados. Neste primeiro momento, os pesquisadores explicitaram os objetivos da pesquisa, apresentaram a documentação de acordo com o compromisso junto ao Comitê de Ética em Pesquisa envolvendo seres humanos, da Universidade Estadual de Londrina, e agendaram a entrevista. A partir do aceite de 16 professores em participar da pesquisa, as entrevistas foram agendadas e ocorreram seguindo um roteiro semiestruturado. As questões do roteiro envolviam: a formação desses professores e suas impressões sobre esse processo; o tempo de experiência profissional; o número de escolas em que cada professor atua; o número de alunos por sala; a infraestrutura física disponibilizada; o tempo semanal programado e realmente destinado para as aulas de Ciências; a articulação realizada entre essa disciplina e as demais; os interesses e as dificuldades de aprendizagem dos alunos; e, finalmente, os problemas e as facilidades enfrentados pelos professores.

As entrevistas foram gravadas e transcritas, e seus dados, após a imersão e geração de categorias, foram tabulados utilizando-se como recurso a estatística descritiva simples a partir da geração de planilhas e gráficos no software Microsoft Excel, abrangendo frequências e porcentagens. Apesar dessa quantificação, um olhar qualitativo sobre os dados não pôde deixar de ser realizado, e, portanto, trechos das entrevistas transcritas foram destacados para permitir uma compreensão mais profunda.

Este trabalho não tem a pretensão de ser uma representação estatística da realidade brasileira. Consiste em um estudo amostral dentro de um determinado contexto e dentro de um determinado momento. Extrapolações requerem estudos com outras composições amostrais.

\section{RESULTADOS E DISCUSSÃO}

Ao se analisarem as respostas dos entrevistados sobre sua própria formação, verificou-se que 14 deles haviam realizado curso de Magistério, que era a formação inicial de nível médio. Todos os professores da presente amostra tinham formação de nível superior com destaque para a Pedagogia, seguido das formações em Normal Superior e História, na proporção indicada no gráfico 1. Dois professores dessa amostra têm uma segunda graduação (um em Letras, outro em Biologia), e dois possuem pós-graduação em Psicopedagogia.

Gráfico 1 - Formação em nível superior dos professores entrevistados 


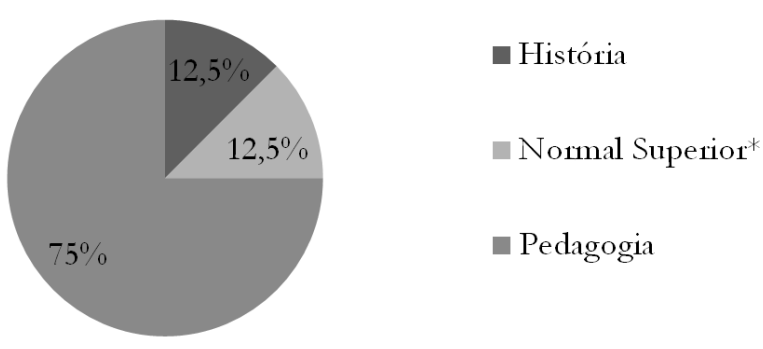

Fonte: os autores.

Percebe-se que esta amostra de professores apresenta um perfil superior àquele apresentado para os professores brasileiros no Censo Escolar de 2016, no qual a formação em nível superior ocorre em 69\% dos professores que atuam nos Anos Iniciais do Ensino Fundamental (BRASIL, 2017). Em sua maioria, além da formação em Nível Superior, os professores têm a formação em Magistério. A idade e a experiência profissional de tais professores ajudam a entender esse percurso, tendo em vista a própria história da formação desse segmento de profissionais. Esta pesquisa realizou entrevistas com professores das mais variadas idades (Gráfico 2). Verificou-se que apenas 25\% são mais jovens com até 29 anos; 31\% têm entre 30 e 40 anos; e os demais $44 \%$ dos professores estão acima de 40 anos de idade. Esses dados vão ao encontro da realidade nacional daquele momento. Segundo o Censo Escolar de 2007, a média de faixa etária dos professores brasileiros do Ensino Fundamental é de 39 anos, e a moda é de 42 anos (BRASIL, 2009).

Gráfico 2 - Idade dos professores entrevistados

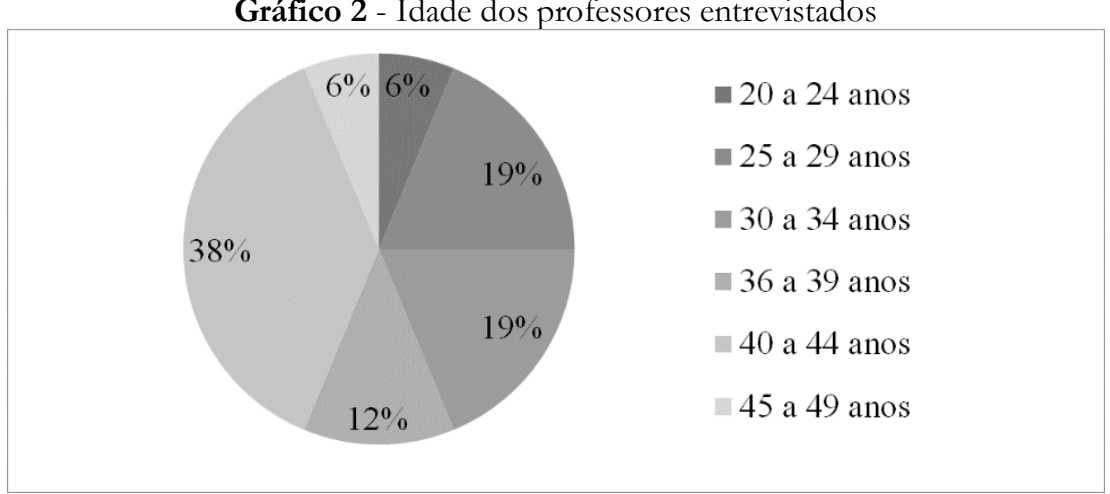

Fonte: os autores.

Pode-se afirmar que essa faixa etária está associada a um perfil profissional de professores mais experientes no magistério. Ao se questionar sobre o tempo de atuação como professor, verificouse que a maioria tem mais de 15 anos de atuação (Gráfico 3) - apenas três professores (18\%) são novatos e atuam até 4 anos na profissão. Esses professores experientes tiveram, portanto, uma trajetória formativa que coincide com o desenvolvimento histórico da formação dos docentes nesse nível de ensino. Passaram primeiramente pela formação no curso de Magistério, que, conforme afirma Saviani (2009), se tornou a Habilitação responsável pela formação de professores em nível médio a partir da década de 1970. Posteriormente, esses professores passaram a se dedicar a uma segunda formação em nível superior, a qual, predominantemente, corresponde ao curso de Pedagogia.

Gráfico 3 - Tempo de atuação no magistério dos professores entrevistados 


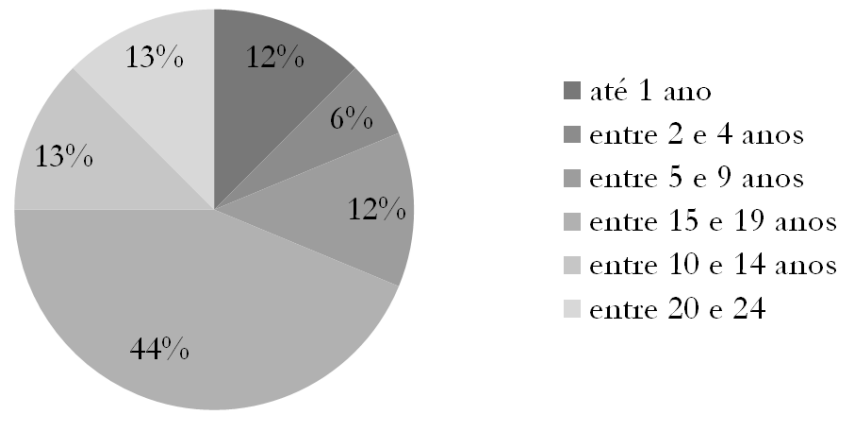

Fonte: os autores.

Esse processo pode ter sido influenciado pelas novas demandas geradas pela LDB 9.394/96 (BRASIL, 2006; BRASIL, 2003; SAVIANI, 2009), que fizeram com que professores que tinham sua formação em magistérios também investissem em uma formação no ensino superior. Pode-se indagar se as novas gerações de professores estão passando pelo mesmo perfil formativo duplo. $\mathrm{Na}$ Universidade Estadual de Londrina, tem-se verificado que, na última década, os alunos ingressantes, em sua maioria, iniciam sua formação docente no curso de Pedagogia sem passar previamente pelo atual Curso de Formação Docente, integrado ao Ensino Médio, ainda que haja alguma oferta desse tipo de curso na região, com cerca de 150 escolas espalhadas por todo o estado do Paraná (PARANÁ, 2018). Uma nova pesquisa para confirmar esta suspeita seria interessante para compreender se essa mudança realmente ocorreu.

Ao se investigar junto aos entrevistados sobre as contribuições de seu curso de formação para a prática docente, notou-se que houve mais menções positivas com relação ao Magistério do que aos cursos de formação em nível superior (Pedagogia e Normal Superior). Há mais egressos do curso de Magistério apresentando uma opinião positiva sobre formação (10) do que negativas (2). Há aqueles também que expressaram tanto argumentos positivos quanto negativos (2). Já os egressos do curso de Pedagogia apresentaram mais equidade entre opiniões positivas e negativas sobre sua formação (três respondentes com opiniões positivas, três com opiniões negativas e dois tanto com opiniões positivas quanto negativas.

Os pontos positivos e negativos de cada curso variaram segundo os professores. Algo que chamou a atenção foi a valorização da presença de aspectos da prática docente, mas sem desconsiderar a importância da teoria. Ora os entrevistados elogiaram seu curso de Magistério justamente por considerá-lo como mais voltado à prática, ora criticaram seu curso de Pedagogia por não trazer esses subsídios.

A professora P1, por exemplo, considerou seu curso de Magistério mais prático, e o curso de Pedagogia, mais teórico, levando-se em conta que as duas formações se complementam: "O Magistério eu acho que é algo mais prático, né? Você aprende a fazer, é trabalho. Eu acho que ele é assim algo mais prático. Agora a Pedagogia, ela te prepara, assim, para com as teorias, né? E assim os dois um complementa o outro (...)" (P1). Todavia, apesar da grande valorização da prática, na qual é ressaltada a preparação para o exercício docente com atividades que possam ser desenvolvidas na sala de aula, a teoria não deixa de ser considerada como um aspecto positivo.

A valorização da conexão entre os aspectos voltados para a prática docente e os teóricos no processo formativo coincide com o observado por Cruz (2002). Seus entrevistados inclusive acreditam que o curso de Pedagogia também esteve, desde seu princípio, voltado para aspectos mais teóricos, não dando o mesmo tratamento aos elementos práticos abordados pelos cursos de formação em nível secundário.

Outro fator que também se destacou nas menções dos entrevistados foi a valorização dos estágios, exatamente pela sua proximidade com a ambiência e os fazeres ordinários do cotidiano escolar. Eles foram positivamente mencionados tanto com relação ao curso de Magistério quanto no que concerne ao curso de Pedagogia. Um exemplo pode ser encontrado na fala do professor P2, sobre sua formação em Pedagogia: “(...) o que a gente aprende ali na prática, nos estágios, é muito importante (...)” 
(P2). Aqui o destaque dado aos estágios tem um duplo significado: a valorização do reencontro com a sala de aula, no contexto de um curso que enfatiza a abordagem teórica, e também a possibilidade de que, nesse momento, o do estágio, haja uma aproximação entre os dois âmbitos: o teórico e o prático.

Os professores ressaltaram também a importância da experiência docente na continuidade de sua formação. Consideram que a formação inicial contribui, mas que se trata de um começo que precisa ser retomado. Portanto, o exercício da profissão também tem, para eles, grande relevância no aprendizado da docência. Ao avaliar sua formação formal nos dois níveis (Magistério e Pedagogia), um dos entrevistados menciona: "Ajudam bastante, mas o que eu deveria ter feito é uma pós que ia ajudar bem mais. O que vale mesmo é a experiência do dia a dia" (P3). Apresenta-se, aqui, uma dupla consideração que pode soar como controversa, mas que, segundo parece, sintetiza o reencontro das duas dimensões formativas que constituem o professor.

Apesar da valorização da prática para a formação de professores, é válido lembrar as palavras de Gimeno-Sacristán (1999, p. 54), que ressalta: "Seria ridículo renunciar à bagagem de informação acumulada, argumentando que o professor só se forma na prática, mas seria igualmente errôneo esperar que todo esse conhecimento substituísse a prova da experiência”. Portanto, ambos, teoria e prática, são relevantes nesse processo e valorizados pelos entrevistados, apesar de a prática ganhar destaque em suas palavras.

Alguns entrevistados mencionaram que consideram importante que a formação forneça subsídios conceituais para as disciplinas que serão posteriormente ensinadas nos Anos Iniciais do Ensino Fundamental. Parte dos docentes elogiou a presença desses aspectos em seu percurso formativo. Já aqueles que não os tiveram, por sua vez, criticaram essa ausência na sua formação.

Com relação à preparação específica para o ensino de Ciências, também houve esse duplo apontamento: enquanto um dos entrevistados elogiou o docente que em sua graduação lhe forneceu conhecimentos conceituais da área, outro entrevistado apontou a falta de subsídios suficientes para o ensino da disciplina. Do ponto de vista da presente pesquisa, as duas colocações convergem para essa necessidade formativa, tomando como referência sua experiência pessoal.

Ao comentar seu percurso formativo, um dos entrevistados afirmou:

Deveria ter sido melhor porque eu acho, assim, que é a mesma coisa: eles trabalham mais para gente dar o Português e a Matemática. Então, eu acho assim, no magistério teria que ser trabalhado mais como a professora trabalhar também Ciências, Geografia e História. Então é na Pedagogia até tive, sabe, a disciplina de Ciências sabe, mas não assim que abrangeu ... é uma coisa assim vaga, né, que só se comenta. (P4).

Pode-se entender aqui como se refletem no percurso formativo as ênfases da política educacional e suas consequências: a centralidade do ensino da leitura e escrita e da matemática, que não são vivenciadas nos momentos de ensino das demais áreas de conhecimento. E, assim sendo, as especificidades de cada área também ficam fora do alcance do futuro professor em formação.

O domínio do conteúdo específico, aspecto problemático da formação do professor dos Anos Iniciais, também foi identificado por outros pesquisadores - como Carvalho e Ramalho (2018), Augusto e Amaral, 2015; Langhi e Nardi, 2005; Longhini, 2008 -, revelando uma preocupação para este nível de ensino: a necessidade de subsidiar os professores com conhecimentos relacionados às Ciências Naturais, ou seja, trata-se de uma questão que permanece sem solução.

Um outro aspecto investigado diz respeito às condições cotidianas que podem também influenciar na prática desse professor e sua relação com a profissão. De acordo com os dados obtidos, $50 \%$ dos entrevistados possuem uma carga maior de trabalho lecionando em mais de um turno (em uma ou mais escolas), ou lecionando em um período e assumindo a função de pedagogo, em outro. Essa porcentagem de professores que dobram sua carga horária é superior àquela identificada no contexto brasileiro no momento da coleta de dados: $92,9 \%$ dos profissionais trabalham em uma única escola, sendo que 69,1\% lecionam para apenas uma turma (BRASIL, 2009).

Zibetti e Pereira (2010) identificaram problemática similar, apontada pelas professoras participantes de sua pesquisa como principais problemas de insatisfação docente: "baixos salários, carga 
horária exaustiva e ausência de horário destinado ao planejamento dentro da jornada de trabalho, obrigando as professoras a levarem atividades da escola para casa" (ZIBETTI; PEREIRA, 2010, p. 266).

Segundo Weber et al. (2015), as três maiores fontes de estresse para professores que atuam em mais de uma escola são: administrar o tempo, a ansiedade profissional, a disciplina e a motivação dos alunos.

Quanto ao número de alunos por sala de aula, verificou-se que metade dos professores entrevistados tinha em suas turmas entre 20 e 25 alunos, e a outra metade tinha entre 26 e 35 alunos (Gráfico 4). Portanto, isso permite diferentes realidades, uma vez que os professores que têm 35 alunos, quando comparados com aqueles que têm até 25 , terão que distribuir sua atenção a um número maior de estudantes.

Gráfico 4 - Número de alunos presentes nas turmas dos professores entrevistados

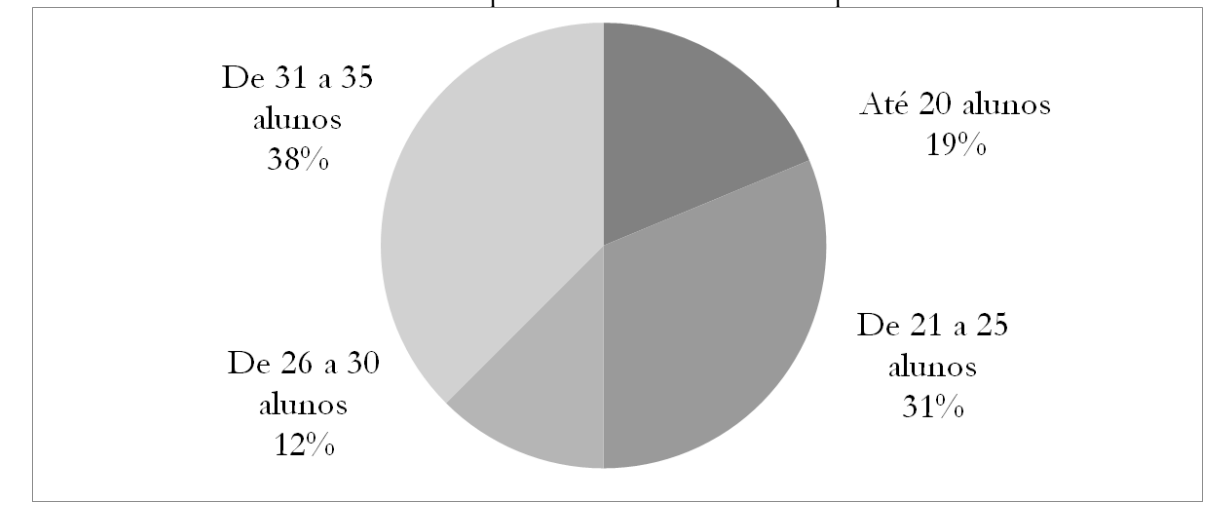

Fonte: os autores.

$\mathrm{Na}$ Tabela 1, verifica-se que todas as turmas de $1^{\circ}$ e $2^{\circ}$ ano têm no máximo 30 alunos, sendo que a maioria engloba até 25 crianças. Quanto às turmas de $3^{\circ}, 4^{\circ}$ e $5^{\circ}$ ano, são em maioria mais numerosas, tendo entre 26 e 35 alunos - apesar de haver aquelas também com um número reduzido de estudantes. Segundo Weber et al. (2015), o número de alunos também está diretamente relacionado ao estresse docente. Os pesquisadores também identificaram uma correlação entre o número de alunos e o fato de o professor se sentir frustrado com problemas de indisciplina na classe.

Tabela 1 - Número de professores por sua quantidade de alunos em cada ano escolar

\begin{tabular}{cccccccr} 
Número de alunos & 10. Ano & 2o. Ano & 3o. Ano & 4o. Ano & 5o. Ano & Total Geral \\
Até 20 alunos & 2 & 0 & 1 & 0 & 0 & 3 \\
De 21 a 25 alunos & 1 & 1 & 0 & 3 & 0 & 5 \\
De 26 a 30 alunos & 0 & 1 & 1 & 0 & 0 & 2 \\
De 31 a 35 alunos & 0 & 0 & 1 & 2 & 3 & 6 \\
\hline Total & $\mathbf{3}$ & $\mathbf{2}$ & $\mathbf{3}$ & $\mathbf{5}$ & $\mathbf{3}$ & $\mathbf{1 6}$
\end{tabular}

Fonte: os autores.

Sobre as condições de espaço e recursos, verificou-se que todos trabalham em escolas que possuem bibliotecas, uma realidade distante da encontrada no resto do País, em que dados do censo escolar mostram que hoje menos de 50\% das escolas possuem este espaço (BRASIL, 2017). Entretanto, apenas quatro entrevistados $(25 \%)$ disseram que há laboratórios em suas escolas. Não consideramos que a escola precise ter um laboratório similar àquele que é usado nos anos finais do Ensino Fundamental ou do Ensino Médio, com vidrarias e bancadas, mas, pelo menos, um espaço com pia, mesas grandes manipulação de materiais, o que seria muito importante para permitir esse tipo de atividade. Para Bomfim e Dias (2013), laboratórios adequados para o ensino de Ciências Naturais são importantes, pois desempenham o papel de dinamizar e enriquecer as aulas desta área de conhecimento e estimular a aprendizagem dos alunos. 
Quanto ao tempo semanal programado para o ensino de Ciências, percebeu-se que os professores apresentam realidades diferentes, conforme se pode verificar no Gráfico 5. A maioria (13 entrevistados, correspondentes a $75 \%$ da amostra) está dividida quase equitativamente em dois grupos: sete respondentes (44\%) dizem delimitar dois ou três dias da semana para trabalhar o conteúdo e afirmam respeitar essa programação; e seis professores $(38 \%)$ informam que não delimitam dias e horários fixos na rotina semanal para o trabalho da disciplina, mas dizem trabalhar semanalmente. Há ainda um pequeno grupo de dois professores $(12 \%)$ que declara trabalhar com a disciplina diariamente.

Gráfico 5 - Número de aulas programadas para o ensino de Ciência por cada professor entrevistado dentro de sua rotina semanal

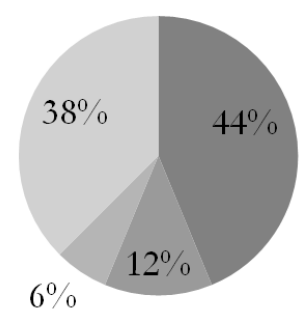

Delimita dois ou três dias da semana para trabalhar com o conteúdo

- Diariamente

Não delimita

Não delimita dias, mas diz abordar semanalmente

\section{Fonte: os autores.}

Um dado que chamou a atenção é que todos os que inserem esta disciplina em seu planejamento mencionam que o ensino de Ciências é programado para a sexta-feira. O outro dia da semana geralmente é a quarta e/ou quinta-feira. Nenhum dos participantes (além dos dois que dizem trabalhar diariamente a disciplina) mencionou iniciar a semana trabalhando Ciências na segunda-feira ou na terça-feira.

Seria esse um indício de que a semana começa com o que é considerado mais importante? O fato é que a priorização de outras áreas de conhecimento é uma prática que acontece, e isto ficou evidente na fala de alguns entrevistados. Um dos professores afirmou que o trabalho com a disciplina está condicionado ao cumprimento de outras prioridades, que são as atividades na área de Língua Portuguesa e Matemática: "Olha Ciências eu dou duas vezes na semana, tá. Então, geralmente é assim, depende muito do Português e da Matemática, se não atrasar. Se atrasar eu vou optar pelo Português e pela Matemática (...)" (P5). Outro exemplo aparece no discurso de outro professor: "Não há previsão, né? Conforme você vai dando os conteúdos, você pode estar colocando o ensino de Ciências ali contextualizado, mas nós focamos mais a alfabetização". (P1).

A literatura já vem apontando há décadas a priorização das disciplinas de Língua Portuguesa e Matemática e, consequentemente uma menor valorização da disciplina de Ciências Naturais, Geografia e História para estes anos iniciais de escolaridade (DELIZOICOV; ANGOTTI, 1990). Segundo Garcia et al. (2018), a cultura de exames de larga escala com ênfase em Língua Portuguesa e Matemática, atrelada a políticas de responsabilização, em que professores e escolas são responsáveis pelo desempenho de seus alunos nesses testes, vem propiciando e sustentando tal prática na atualidade. Essa cultura faz com que as preocupações nas instituições de ensino girem em torno de se atingirem os resultados e métodos nas áreas priorizadas, possivelmente influenciando parte dos professores aqui pesquisados, que consideram que há outras prioridades na dianteira do Ensino de Ciências Naturais. Apenas um professor relata que o ensino de Ciências é algo central em seu trabalho: "Na verdade eu trabalho com um projeto de horto medicinal, então a minha aula é basicamente em cima da área de Ciências" (P6).

Quanto ao trabalho integrado dos conteúdos dessa área de conhecimento com outras, a maioria dos professores declara realizá-lo (14 dos respondentes, equivalente a 94\%). Um dos entrevistados diferenciou-se dos demais, pois afirmou que o trabalho da escola não é separado por 
disciplinas: "Bom, nós temos uma metodologia diferente, então as aulas de Ciências são previstas para todo momento, pois nós não separamos em matérias" (P7).

Outros professores também comentam a articulação entre os conhecimentos de diferentes áreas, sem mencionar um trabalho de forma mais especificada, evidenciando que suas escolas mantêm a divisão da abordagem dos conhecimentos por disciplina e que, por vezes, procuram realizar as chamadas integrações:

Sim, às vezes, né, tá trabalhando um tema interdisciplinar. Eu acho que não tem como você falar de Ciência sem entrar dentro de outras disciplinas, né? Na Língua Portuguesa, mesmo, a gente trabalha muitos textos. Dentro mesmo, né, questão de espaço mesmo, a gente tá trabalhando Geografia ou História. A gente lembra os inventores e as descobertas. Enfim, a gente acaba trabalhando dentro de, fazendo uma articulação das outras disciplinas (P2).

Uma outra iniciativa também foi mencionada pelo professor P8 quando informou que está tentando realizar um trabalho mais conectado e, para tanto, está procurando ajuda de outra professora mais experiente:

A gente está tentando... eu e a outra professora, a gente está tentando trabalhar em conjunto, né? Ela tem bem mais experiência do que eu e ela está tentando me ajudar com isso. E a gente tenta fazer isso mesmo: vai passar um textinho ali passando algum conteúdo, então vamos fazer uma interpretação de texto em cima daquilo ali, vamos fazer uma atividade de ortografia em cima daquele texto. A gente tenta trabalhar em conjunto mesmo, até porque como eles estão aprendendo agora estrutura do texto, como se constrói, a gente faz produção de texto com conteúdo de Ciências. Então, a gente tenta trabalhar junto sim. (P8).

Santana, Capecchi e Franzolin (2018) verificaram que é possível que professores, nos Anos Iniciais, ao trabalharem com atividades investigativas no ensino de Ciências Naturais, dialoguem com outras áreas de conhecimento, o que pode ocorrer também pela produção de texto. Existe uma variedade de possibilidades, como o trabalho com medidas, a construção de gráficos, de tabelas, a leitura de textos, a elaboração de registros e a apresentação de resultados e conclusões das investigações em diferentes linguagens. Na perspectiva do caso do ensino por investigação, conhecimentos de Língua Portuguesa e Matemática auxiliam na resolução de um problema investigativo, propiciando conexões que vão além das narradas pelos participantes desta pesquisa.

Outro aspecto investigado foi o interesse das crianças pela disciplina de Ciências. Apenas um dos professores $(6 \%)$ afirmou que seus alunos manifestam pouco interesse; porém, alertou que esse desinteresse de seus alunos não se restringe ao ensino da disciplina em si, mas compreende também as demais disciplinas. Os outros entrevistados (94\%) apontaram que seus alunos se interessam pela disciplina de Ciências. Dois destes professores não expressaram gradação quanto ao gosto pela disciplina, mas $81 \%$ dos professores disseram que seus alunos mostram muito interesse pelos assuntos da área. Metade desta amostra enfatizou esse sentimento das crianças com afirmações como as que se seguem:

Nossa bastante! (P5)

Se interessam bastante. Eles participam adoram. Sabe, pesquisar, fazer atividades diferenciadas, eles, eles participam bastante. (P2).

Eu acho que as crianças, elas ficam, assim, deslumbradas com o ensino de Ciências, elas adoram o ensino de Ciência. (P9)

Muitoo! (P10, esse professor respondeu com risada e muita ênfase girando a cadeira que estava sentado).

Esses dados acabam por fornecer indícios de que haveria um grande potencial para o ensino de Ciências, assim como, a partir dele, seria possível estabelecer uma conexão com as demais áreas de conhecimento, articulando leitura e escrita, tanto de textos como de tabelas e gráficos.

Quanto à curiosidade das crianças, quando solicitados a fornecer exemplos de perguntas que elas realizavam, verificou-se que as questões estão relacionadas aos mais diversos tópicos do 
conhecimento científico. Entretanto, nota-se que assuntos ligados à zoologia, à fisiologia humana e à astronomia foram os mais mencionados (Gráfico 6).

Gráfico 6 - Tópicos de Ciências que despertavam a curiosidade das crianças, segundo seus professores

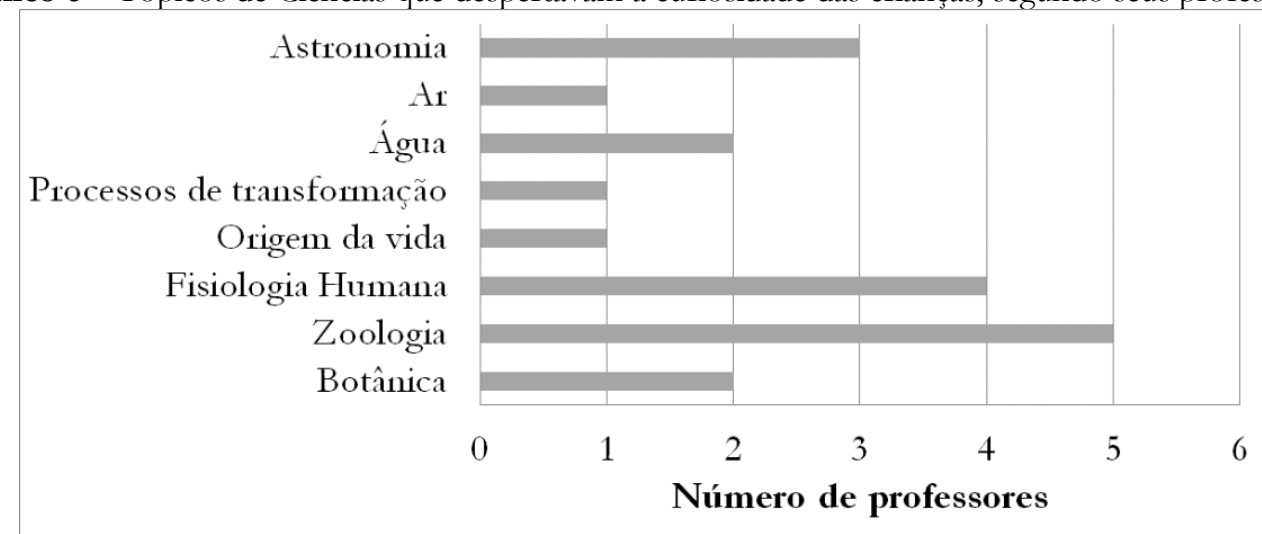

Fonte: os autores.

Um exemplo relacionado à área de zoologia pode ser evidenciado na fala do seguinte professor: "Olha nós estudamos a respeito dos animais: de onde veio, ou então, como que nasceu, ou então sobre os ovos, os animais ovíparos. Aí eles querem saber de tudo, e as perguntas vão longe [...]" (P3).

Outras perguntas são mencionadas por outros professores:

Por que o peixe não morre na água quando respira? (P7);

Se um inseto está lá na horta, também está trabalhando, quantas patas tem? (P11);

Se a gente pegar aquele exemplo que eu dei da lagartinha, é aí, da onde veio? Como veio? [...] por que a minhoca está embaixo da terra? [...] (P12).

Sobre a fisiologia humana, por exemplo, o professor P1 comenta sobre as dúvidas de seus alunos: "Ah, eles perguntam as mudanças do corpo. As vezes olham na gente, principalmente as meninas. Daí eles ficam curiosos para saber as informações" (P1).

No que se refere à identificação das dificuldades de aprendizagem em Ciências por seus alunos, notou-se um destaque na questão relacionada à interpretação de textos e ao pouco interesse pela leitura. Houve também quatro professores $(25 \%)$ que dizem não identificar dificuldades nos alunos quanto ao aprendizado na disciplina (Gráfico 7).

Gráfico 7 - Dificuldades de aprendizagem em Ciências apontadas pelos professores.

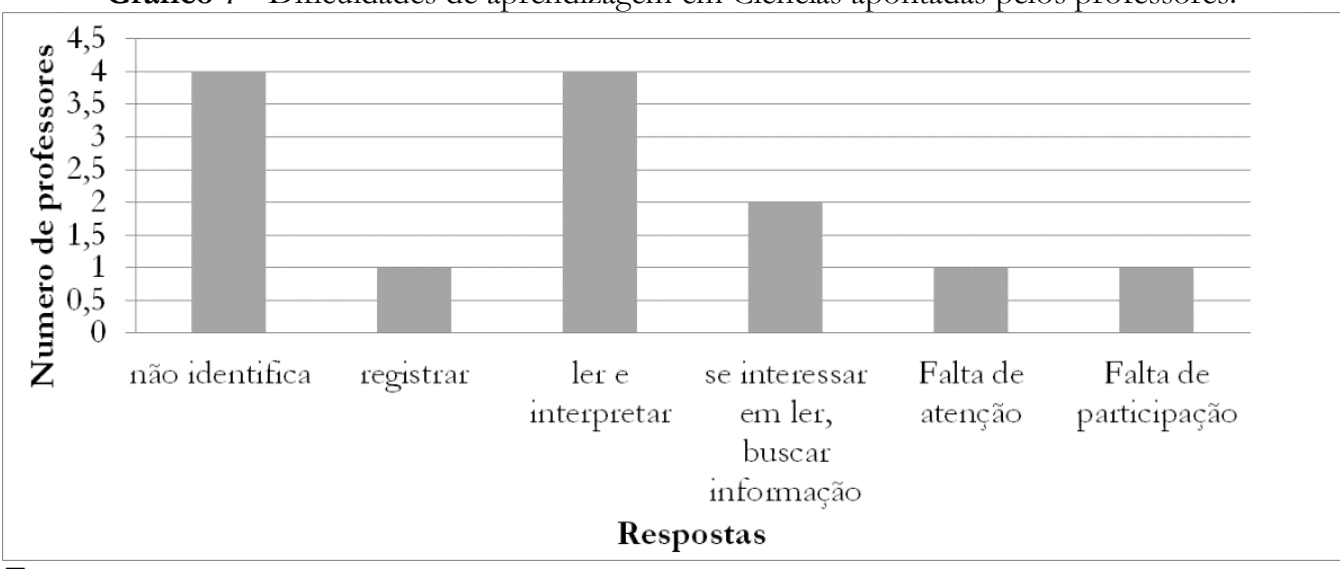

Fonte: os autores.

Quando solicitados a se pronunciarem sobre suas dificuldades para ensinar Ciências, cerca da metade dos professores (56\%) mencionaram ter dificuldades, apresentando motivos variados. O mais 
citado foi a ausência de materiais; entretanto, outros relativos às condições de trabalho também foram mencionados, tais como: falta de espaço (laboratório e sala de informática), salas de aula numerosas e falta de domínio, por parte do professor, dos conteúdos a serem ministrados. A indisciplina dos alunos também foi mencionada por um professor (Gráfico 8).

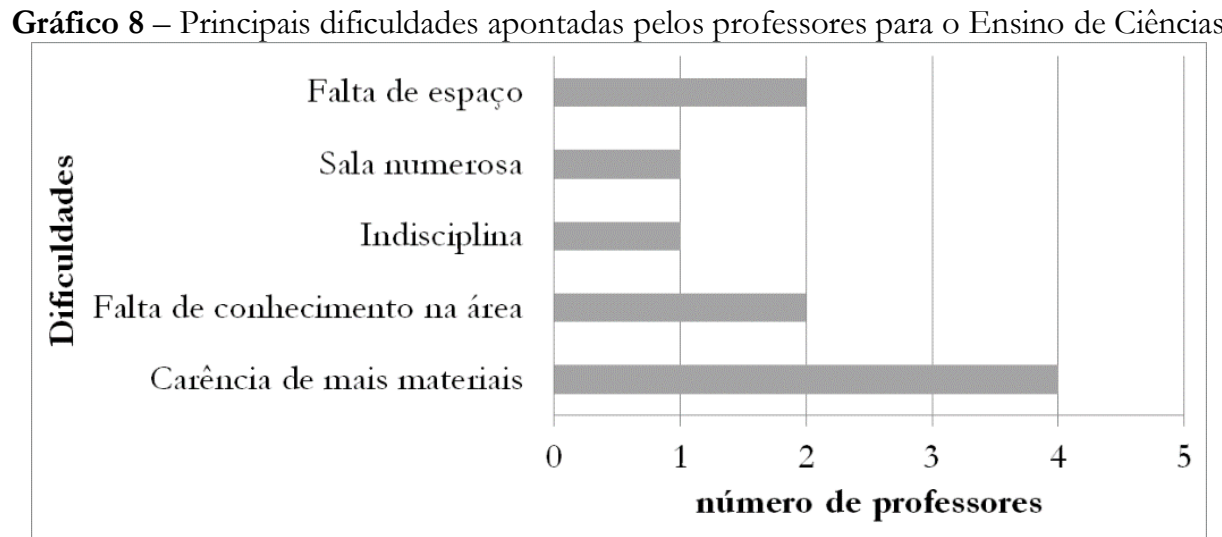

Fonte: os autores.

Dentre os professores que afirmaram não terem dificuldades para ensinar Ciências, duas razões foram apontadas para essa situação: um dos entrevistados disse que tem facilidade em ensinar a disciplina, pois já é um professor experiente; outros três justificaram sua facilidade pelo fato de haver vários materiais à sua disposição, dando-lhes subsídios.

Assim, no levantamento de dados sobre o contexto, percebe-se que as dificuldades não são apenas decorrentes da formação, e, sim, como aponta Paro (2012), referem-se a múltiplos fatores relacionados às condições nas quais o docente atua.

\section{CONSIDERAÇÕES FINAIS}

Nesta pesquisa, investigou-se como os professores analisam a contribuição dos cursos voltados para a formação dos professores dos Anos Iniciais do Ensino Fundamental visto a posteriori, isto é, à luz de sua atividade profissional e, neste contexto, como avaliam as condições de trabalho para o Ensino de Ciências nessa etapa da escolaridade.

Ao se analisarem os dados coletados por meio de entrevistas, concluiu-se que a amostra de professores de Londrina (PR) se constitui de profissionais tanto com formação no curso de Magistério, como no curso de Pedagogia - formação superior àquela evidenciada nos dados Brasileiros (BRASIL, 2017). Essa trajetória de dupla formação pode ser explicada pela faixa etária dos entrevistados, a maioria com idade superior aos 30 anos e com mais de 15 anos na docência. Desse modo, vê-se um perfil formativo que retrata a história da formação de professores evidenciada na literatura (SAVIANI, 2009), segundo a qual professores inicialmente com formação no curso de Magistério foram levados pela LDB 9.394/96 a cursar o Ensino Superior. Entretanto, dados do cotidiano acadêmico, que fogem do escopo desta pesquisa, levam à suposição de que esse perfil esteja se alterando nas novas gerações de professores, os quais procuram se formar diretamente no curso de Pedagogia, o que pode ser confirmado em futuras pesquisas.

Verificou-se, entretanto, que aqueles que passaram pela formação em Magistério destacam considerações positivas para esse curso. Quanto ao curso de Pedagogia, houve mais equilíbrio entre considerações positivas e negativas. Um dos itens de valorização ou desvalorização é a relação do curso com a prática docente, sem, entretanto, negar a importância da teoria. Ademais, independentemente do curso, foi recorrente na fala dos entrevistados a importância atribuída ao estágio e a valorização do aprendizado que se dá com o exercício da profissão. A atenção para com o domínio do conteúdo específico também apareceu na fala de parte dos entrevistados, havendo quem ressaltasse que essa foi contemplada em sua formação; houve, contudo, quem reclamasse sua ausência. Conhecer as visões dos docentes sobre suas realidades formativas propicia que se estabeleçam, além de conhecimentos 
intrínsecos sobre estas em diferentes contextos e tempos, reflexões sobre o que valorizam, suas demandas e necessidades, possibilitando o fomento dos cursos.

Todavia, concordando com Paro (2012), procurou-se não apenas olhar para a formação para compreender a situação docente. Verificaram-se outros aspectos de seu cotidiano evidenciando fatores que podem influenciar na qualidade do ensino, tais como: o fato de que metade dos entrevistados dobram seu período de trabalho; a conjuntura de que há tanto professores com turmas numerosas quanto aqueles que estão em salas com um número mais reduzido de alunos; e a realidade de poucas escolas possuírem laboratórios, ao passo que todas as escolas nas quais os entrevistados atuam dispõem de bibliotecas.

Os dados ainda mostraram que os professores relatam trabalhar com Ciências. Todavia, o fato de a disciplina nunca ser ministrada no início da semana e o relato de alguns docentes mostram que outras áreas de conhecimento, como Língua Portuguesa, estão dentre suas preocupações principais. A maioria dos professores, entretanto, diz que seus alunos se interessam muito pela disciplina, a qual, por esta razão, poderia ser mais bem aproveitada se o professor utilizasse seu ensino tanto para desenvolver os conhecimentos específicos da área como para contribuir para o aprendizado da língua materna.

As dificuldades apontadas pelos professores não estão apenas relacionadas à sua formação: mencionam as dificuldades de interpretação de texto pelos alunos, a ausência de materiais ou espaço adequado, entre outras condições de trabalho. Por fim, considera-se que o conhecimento de tais aspectos pode levar à reflexão sobre elementos importantes para o fomento do Ensino de Ciências. Nesse caso, defende-se tanto a valorização de uma formação que contemple mais a preparação para a prática docente quanto também a necessidade de melhores condições de trabalho para o professor. É preciso espaço adequado para trabalhar e mais tempo para se dedicar a seus alunos, sem sobrecarga de número de discentes ou de turnos de trabalho. Ademais, pode-se ainda defender a necessidade de políticas que levem à valorização do Ensino de Ciências como uma disciplina importante para os Anos Iniciais do Ensino Fundamental, ao contrário do que hoje ocorre (GARCIA et al., 2018).

A formação continuada promovida com a participação das universidades vem se constituindo em uma possibilidade promissora na medida em que proporciona ao profissional uma reinserção na universidade local, onde pode compartilhar os conhecimentos adquiridos com a sua prática como docente e também adquirir outros, advindos das pesquisas e dos estudos que são realizados nessas instituições. Entretanto, um complicador dentro desse contexto tem sido a descontinuidade dos programas instituídos, as reorientações sucessivas e o alcance restrito, tendo-se em vista as dimensões das redes de ensino públicas do País.

\section{AGRADECIMENTOS}

Agradece-se aqui o fomento destinado a esta pesquisa pelas seguintes instituições: Fundação Araucária de Apoio ao Desenvolvimento Científico e Tecnológico e Universidade Estadual de Londrina.

\section{REFERÊNCIAS}

AUGUSTO, Thaís G. S.; AMARAL, Ivan A. A formação de professoras para o ensino de ciências nas séries iniciais: análise dos efeitos de uma proposta inovadora. Ciência \& Educação, v. 21, n. 2, p. 493-509, 2015.

BATISTA, Michel C.; FUSINATO, Polonia A.; RAMOS, Fernanda P. A formação de professores dos Anos Iniciais para o ensino de astronomia no Estado do Paraná. Ensino \& Pesquisa, v. 14, n. 2, p. 214231, jul./dez. 2016.

BATISTA, Eliane R. M.; LIMA, Tânia M. Formação de professores no curso de Pedagogia e o Ensino de Ciências: uma análise da produção científica. RECH-Revista Ensino de Ciências e Humanidades Cidadania, Diversidade e Bem Estar, v. 1, n. 1, p. 336-358, jul./dez. 2017.

BOMFIM, Grecilane F.; DIAS, Viviane B. Aulas de Ciências Naturais em escolas de Ensino Fundamental I: relações existentes entre a estrutura física dos laboratórios e a realização de atividades 
experimentais. In: ENCONTRO NACIONAL DE PESQUISA EM EDUCAÇÃO EM CIÊNCIAS, 9., Águas de Lindóia, 2013. Anais... São Paulo: ENPEC, 2013.

BRASIL. Instituto Nacional de Estudos e Pesquisas Educacionais Anísio Teixeira. Estudo exploratório sobre o professor brasileiro com base nos resultados do Censo Escolar da Educação Básica 2007. Brasília: Inep, 2009.

BRASIL. Instituto Nacional de Estudos e Pesquisas Educacionais Anísio Teixeira. Censo Escolar da Educação Básica 2016: Notas Estatísticas. Brasília: Inep, 2017.

BRASIL. Instituto Nacional de Estudos e Pesquisas Educacionais Anísio Teixeira. Censo Escolar da Educação Básica 2018: Notas Estatísticas. Brasília: Inep, 2019.

BRASIL. Lei de Diretrizes e Bases da Educação Nacional n 9394/96, de 20 de dezembro de 1996. Estabelece as diretrizes e bases da educação nacional. Diário Oficial [da] República Federativa do Brasil, Brasília, seção 1, p. 27833, 23 dez. 1996.

BRASIL. Parecer nº. CEB 03/2003. Diário Oficial da União, Conselho Nacional de Educação, Brasília, DF, 14 ago. 2003. Disponível em: http://portal.mec.gov.br/cne/arquivos/pdf/pceb003_03.pdf. Acesso em: 12 jan. 2018

BUENO, Kely C. A utilização de recursos, procedimentos e espaços escolares nas aulas de ciências naturais dos anos iniciais do Ensino Fundamental. 2017. 152 f. Dissertação (Mestrado em Ensino e História das Ciências e da Matemática). Santo André: Universidade Federal do ABC, 2017.

CARVALHO, Clévia S. C.; RAMALHO, Betania L. O ensino das Ciências da natureza nos anos iniciais da escolarização básica: das necessidades formativas à profissionalização docente. Revista Entreideias, Salvador, v. 7, n. esp, p. 107-126, 2018.

CRESPI, Livia; NÓBILE, Márcia F. Trajetória histórica do curso de graduação em Pedagogia: principais documentos legais e contexto atual da oferta no Brasil. Reveduc, v. 12, n. 2, p. 319-335, maio/ago. 2018.

CRUZ, Giseli B. Teoria e prática no curso de pedagogia. Educação e Pesquisa, São Paulo, v. 38, n. 1, p. 149-164, 2012.

DELIZOICOV, Demétrio; ANGOTTI, José André. Metodologia do ensino de ciências. São Paulo: Cortez, 1990.

GARCIA, Paulo S.; FAZIO, Xavier; PANNIZZON, Debra; BIZZO, Nelio. Austrália, Brasil e Canadá: impacto das avaliações no ensino de Ciências. Estudos Em Avaliação Educacional, v. 29, n. 70, p. 188-221, 2018.

GATTI, Bernardete A.; NUNES, Marina M. R. (Orgs.). Formação de professores para o ensino fundamental: estudo de currículos das licenciaturas em pedagogia, língua portuguesa, matemática e ciências biológicas. São Paulo: FCC/DPE, 2009.

GIMENO-SACRISTÁN, J. Poderes Instáveis em Educação. Porto Alegre: Artmed, 1999.

HAMBURGER, Ernst W. Apontamentos sobre o ensino de Ciências nas séries escolares iniciais. Estudos Avançados, v. 21, n. 60, p. 93-104, 2007. 
LANGHI, Rodolfo; NARDI, Roberto. Dificuldades de professores dos anos iniciais do ensino fundamental em relação ao ensino da astronomia. Revista Latino-Americana de Educação em Astronomia RELEA, n. 2, p. 75-92, 2005.

LONGHINI, Marcos D. O conhecimento do conteúdo científico e a formação do professor das séries iniciais do Ensino Fundamental. Investigações em Ensino de Ciências, Porto Alegre, v. 13, n. 2, p. 241-253, 2008.

PARANÁ. Formação de Docente - Oferta do Curso. Secretaria da Educação. Disponível em: http://www.comunidade.diaadia.pr.gov.br/modules/conteudo/conteudo.php?conteudo=137. Acesso em: 12 maio 2018.

PARO, Vitor. H. Reprovação escolar: renúncia à educação. 2a . ed. São Paulo: Xamã, 2003.

PARO, Vitor H. Trabalho docente na escola fundamental: questões candentes. Cadernos de Pesquisa, v. 42, n. 146, p. 586-611, maio/ago. 2012.

PROVÍNCIA DO RIO DE JANEIRO. Decreto de criação da Escola Normal no 10 de abril de 1835. Disponível em: https://repositorio.ufsc.br/handle/123456789/99970. Acesso em: 07 fev. 2018.

RAMOS, Luciana B.; ROSA, Paulo R. O ensino de ciências: fatores intrínsecos e extrínsecos que limitam a realização de atividades experimentais pelo professor dos Anos Iniciais do Ensino Fundamental. Investigações em Ensino de Ciências, v. 13, n. 3, p. 299-331, 2008.

SANTANA, Ronaldo S.; CAPECCHI, Maria C.; FRANZOLIN, Fernanda. O ensino de ciências por investigação nos anos iniciais: possibilidades na implementação de atividades investigativas. Revista Electrónica de Enseñanza de las Ciencias, v. 17, n. 3, p. 686-710, 2018.

SAVIANI, Dermeval. Formação de professores: aspectos históricos e teóricos do problema no contexto brasileiro. Revista Brasileira de Educação, v. 14, n. 40, p. 143-155, jan./abr. 2009.

TANURI, Leonor M. História da formação de professores. Revista Brasileira de Educação, n. 14, p. 61-88, 2000.

THOMPSON, Paul. 1935 - A voz do passado: História oral. Rio de Janeiro: Editora Paz e Terra, 1992.

WEBER, Lídia N.; LEITE, Célio R.; STASIAK, Gisele R.; SANTOS, Cristiani A.; FORTESKI, Rosina. O estresse no trabalho do professor. Imagens da Educaşão, v. 5, n. 3, p. 40-52, 2015.

ZIBETTI, Marli L.; PEREIRA, Sidnéia R. Mulheres e professoras: repercussões da dupla jornada nas condições de vida e no trabalho docente. Educar em Revista, n. 2, p. 259-276, 2010.

Submetido: $26 / 09 / 2020$

Aprovado: $07 / 07 / 2021$ 